\title{
Analysis and Construction on Collaborative Management and Service Platform for Postgraduate in Design Major Based on Tripartite Needs
}

\author{
Delai Men ${ }^{1}$, Chang Xiao ${ }^{1^{*}}$, Mingyi Wang ${ }^{1}$ and Huagang Chen $^{2}$ \\ ${ }^{1}$ School of Design, South China University of Technology, Guangzhou 510006, China \\ ${ }^{2}$ Faculty of Art and Design, Guangdong Baiyun University, Guangzhou 510450, China \\ * Corresponding author
}

Keywords: Tripartite needs; graduate management system; design discipline

\begin{abstract}
Information technology has become an important management mode in higher education management system. In the management of design graduates, it is easy to appear the phenomenon of "information blind zone" of tutors, students and administrative departments. Existing research is seldom based on tripartite needs and design discipline. The purpose of this study is to strengthen the connection between tutors and students, standardize management, and provide disclosure and communication platform to students with targeted information via a series of surveys and interview, collecting and analyzing the existed problems in the process of graduate cultivation and in-depth understanding and combing of the existing problem of graduate management system(GMS), this study finds the necessity which to build a management and service platform for graduate students who major in design based on tripartite administration. Taking the school of South China University of Technology as an example, the model is constructed, which provides an executable and application in tripartite administration and service platform system for reference graduate students in design.
\end{abstract}

\section{Introduction}

In the 70s of last century, Massachusetts Institute of Technology proposed a digital campus model. Gradually graduate management information system has become an important part of the construction of digital campus. According to the data released by ADUCAUSE (2001), all the 1000 colleges and universities in the United States have set up special management departments for campus information construction to take charge of the construction of network infrastructure management system, teaching information and so on [1]. This shows that schools attach importance to the education management system. According to the analysis of digital management of these universities, most of them pay more attention to the provision of digital resources, and they are less stressed integrated system with the relative weakening of management information system.

In recent years, with the development of higher education and the popularity of the Internet, the informatization construction of higher education institutions has also developed rapidly. When GMS is applied to a specific university, it needs to be improved according to the actual situation of the school and the subject to strengthen the system flexibility [2]. Graduate management directly affects the quality of graduate education. The current GMS mostly stays at the level of enrollment and examination, information disclosure, and educational affairs. There are many shortcomings in terms of usability, completeness, and interactivity [3]. Therefore, it is necessary to construct the development and application of graduate tripartite collaborative management and service system (GMCMSS), to strengthen the connection between tutors and students, to standardize graduate management, and to provide students with targeted public information and communication platform for graduate student.

The study aim is to improve the collaborative, efficiency and integrated functions of the graduate management and service platform, of the university design discipline, and to achieve the goal of strengthening the connection between the tutor and the students, in order to standardize the graduate management, and provide students with targeted information disclosure and communication platforms. The study objectives is to analyze the effectiveness of collaborative information management among graduate students, tutors, and administrators, and find out the main functional points applicable to graduate management service platforms 
in design disciplines; To construct GMCMSS plan based on PC and mobile, and apply to the management of graduate students in design .

\section{Methods}

\subsection{Literature Review.}

In order to master the development of management and service system in the process of graduate education, understanding the advantage of the functions and structure is needed to an advanced and representative graduate management and service system. On the basis of literature review, we find out the common problems and challenges, as well as the difference via comparison among representative universities. Through in-depth communication with graduate students, tutors and administrator in various countries, the similarities and differences of management and service systems for graduate students in countries are drawn and the reasons are also explored for avoiding blindness in study and linearity in thinking.

\subsection{Survey.}

In this study, it use multiple survey methods such as observation, problem lists, questionnaires, interviews, case studies and tests to information on graduate education and cultivation, and make a scientific analysis to the current status. Purpose for mastering the status of graduate education in China, in-depth interviews and questionnaires were conducted among graduates, tutors and administrator and investigate the existing educational system and websites, for the representative in the expressed strongly and the system designed will be more applicable.

\section{Primary Study}

\subsection{Questionnaire.}

The study randomly selected 31 design tutors/graduate students from well-known institutions of higher education in May, 2018, and conducted a questionnaire survey on the usage of the master's GMS in the design discipline. The sample has certain representativeness. Through the questionnaire survey, the demand, availability, ease to use and experience of the graduate management service platform are expected judged: design discipline master's supervisor and graduate student, including 24 tutors $(77.42 \%)$ and 7 graduate students (22.58\%) from Tsinghua University, Tongji University, Beijing Film Academy, Hong Kong Polytechnic University and so on (nearly 30 well-known domestic and foreign colleges and universities) were selected to join the survey. According to the statistical analysis of the questionnaires, $87.1 \%$ of the respondents believed that it was necessary to use an exclusive management system or platform with discipline characteristics for the management of graduate students in design disciplines; $67.74 \%$ of the respondents said that their college did not have such a system or platform.

Table 1 Data statistics from questionnaire on usage of management system for graduate student in design, $n=31$

\begin{tabular}{|c|c|c|c|c|c|}
\hline NO. & $\begin{array}{r}\text { Question } \\
\end{array}$ & Yes & No & N/A & Answer \\
\hline 1 & $\begin{array}{l}\text { Does your university use graduate } \\
\text { management system or platform? }\end{array}$ & $18(58.06 \%)$ & $13(41.94 \%)$ & $0(0 \%)$ & \\
\hline 2 & $\begin{array}{l}\text { Do you think it is necessary to use a set of } \\
\text { proprietary management systems or platforms } \\
\text { with discipline characteristics for graduate } \\
\text { management in design disciplines? }\end{array}$ & 27 (87.1\%) & $4(12.9 \%)$ & $0(0 \%)$ & \\
\hline 3 & $\begin{array}{l}\text { Does your design school have such a } \\
\text { proprietary management system or platform? }\end{array}$ & $10(32.26 \%)$ & $21(67.74 \%)$ & $0(0 \%)$ & \\
\hline \multirow{6}{*}{4} & \multirow{6}{*}{$\begin{array}{l}\text { Open question and answer: if so, what are the } \\
\text { basic functions of a system or platform? } \\
\text { (Multiple Choice), } n=10\end{array}$} & $8(80 \%)$ & & & Assignment submission \\
\hline & & $4(40 \%)$ & & & $\begin{array}{l}\text { Meeting / conversation } \\
\text { record }\end{array}$ \\
\hline & & $9(90 \%)$ & & & Calendar schedule \\
\hline & & $7(70 \%)$ & & & data analysis \\
\hline & & $3(30 \%)$ & & & Monitoring tips \\
\hline & & $8(80 \%)$ & & & Other (please list) \\
\hline
\end{tabular}




\section{Cont. to Table 1}

\begin{tabular}{|c|l|l|l|l|}
\hline \multicolumn{2}{|c|}{ Cont. to Table 1 } \\
\hline 5 & $\begin{array}{l}\text { If there is such a platform, the existing system } \\
\text { or platform has problems (quantitative } \\
\text { analysis) }\end{array}$ & $\begin{array}{l}\text { (a) Interactive design is not friendly; (b) Function operation is complex; (c) } \\
\text { Inconvenient use in the off-campus network; (d) Poor compatibility of some } \\
\text { functions to browsers; (e) No APP or Wechat applets and other mobile versions. }\end{array}$ \\
\hline 6 & $\begin{array}{l}\text { If there is no such platform, do you have the } \\
\text { intention to use it? }\end{array}$ & $\begin{array}{l}19 \\
(61.29 \%)\end{array}$ & $2(6.54 \%)$ & 10 (32.26\%) \\
\hline 7 & $\begin{array}{l}\text { Open question and answer: what are the main } \\
\text { problems facing the design discipline graduate } \\
\text { training management? (quantitative analysis) }\end{array}$ & $\begin{array}{l}\text { (a) Graduates generally prefer to work part-time in design institutes or institutions, } \\
\text { or in their own studios, and spend limited time in their studies; (b) Students in design } \\
\text { disciplines are more casual and more difficult to manage than science and } \\
\text { engineering students; c) There is no standardized management system, which relies } \\
\text { too much on manpower; (d) There is a lack of continuous record of the student's } \\
\text { training process for effective evaluation and improvement; (e) Lack of exclusive } \\
\text { platform for submission, group discussion, cutting-edge scientific research and } \\
\text { academic information sharing for design disciplines. }\end{array}$ \\
\hline
\end{tabular}

\subsection{Case Study.}

Through interviewing students, tutor, administrator and browsing the typical GMS of design disciplines, such as: Tsinghua University (China), Lehigh University (USA), De Montfort University (UK) etc., fund that De Montfort University (GMS for the British Gold Management System), considering the needs of the three parties typicality. This system carries out all-information management, with strong interactivity, and continuously records the graduate research progression, and promotes close contact among the tutor, graduate students and graduate schools. The three parties have an intuitive and clear understanding of the graduate academic progression. The inadequacy of the GMS at De Montfort University is: (a) The GMS appearance is more dense without aesthetically perception; (b) There is no proprietary system for the design discipline; and (c) There is no simplified version for the mobile terminal. Through the analysis of typical cases, retain and draw on the relevant advantages, for the optimization reference of future system design.

\section{Results and Analysis}

Through questionnaires, interview and case analysis, the existing problems and optimization platform solutions are fund, for optimization strategies proposed in future research.

\subsection{The Characteristics of students in design disciplines.}

(a) Graduates generally prefer to work part-time in design or institutions, or to create studios. It's not convenient to manage; (b) They are fastidious in aesthetics and have higher requirements for system interface design.

\subsection{The requirements of the design discipline for the system.}

(a) A more compact management model, a standardized management system, less dependent on manpower; (b) Subject-specific evaluation indicators, such as exhibitions, works, competitions, etc.; (c) Functions need to be added such as submission of work for design subjects, group discussion, and sharing of cutting-edge scientific research and academic information.; (d) Continuous record of students' training process for effective assessment and improvement.

\section{Construction of GMCMSS}

\subsection{The Logical Framework.}

The platform of this research is intended to set up three roles: graduate students, tutors and management departments. Students need to complete the training courses, lectures, papers, publication and degree applications, etc. The tutor courses to graduate students, arranges scientific research tasks, and provides paper counseling and work guidance, etc. The management department manages, supervises, evaluates and publishes information about graduate students and tutors, etc.

\subsection{Functional Module Design of the Platform.}

(a) Course Management: The tutor sets the course information in the course module, uploads the learning materials, and publishes the assignment requirements for the students to view and download. The student submits the assignment/work through the course management module, and get feedback. At the results of the 
check, the tutor evaluates, revise and archives the student's assignment/work; (b) Project Management: The tutor sets project information in the research project module, uploads relevant materials, and assigns scientific research tasks for students to view and download. Students submit assignment/work in this module, the tutor gives feedback on the student's assignment/work; (c) Academic Progress Management: The management department will schedule the time for the course assessment, degree application, etc. in the training program. All three parties can see whether the student's affairs have been completed; (d) Monthly Report Records: Mentors and graduate students hold at least one monthly meeting to communicate academic progress and discuss. After that, the student will record the meeting and submit it to the tutor for feedback and make the next arrangement; (e) Electronic Calendar: displaying courses, meetings, lectures and other arrangements within a week; (f) Management Department: The system carries out supervision and data statistical analysis. If the plan is not completed before deadline, the system will send a message to remind the tutor and graduate students. It is also used for applications such as taking personal leave, sick leave and temporary leave etc. of tutors and graduates.

\subsection{Model Framework}

Ease of use, convenience and universality is the guidence in GMCMSS construction. By observing the functions and experience of the graduate cultivation management service system in colleges and universities, as well as carding the problem in graduate student process, a GMCMSS which suitable for graduate education in design discipline is constructed to meet the new requirements of the current system according to the concepts of ease of use, convenience and versatility (Fig. 1). It will be developed and applied in the next stage.

\section{Graduate}

Tutor

Administration department

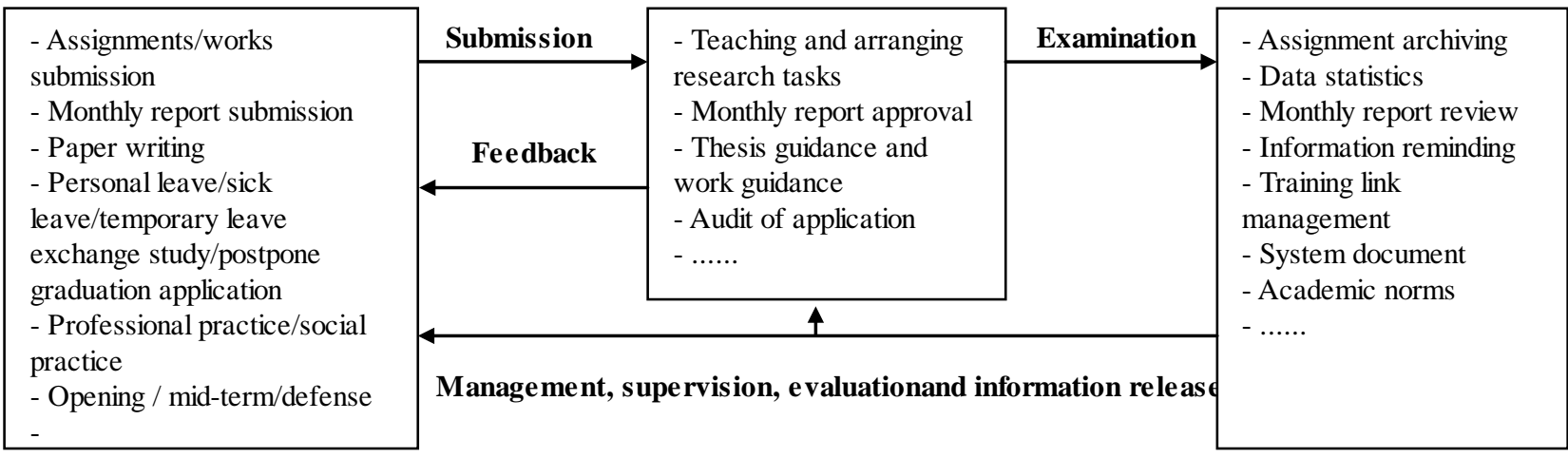

Fig. 1 Design framework of multi-disciplinary collaborative management service platform

\subsubsection{Graduate Terminals.}

The academic tasks of graduate students throughout the learning phase include courses, lectures, publishing journals/conference papers, writing dissertations, participating in professional/social practice, and conducting degree application defense; The task of research is assigned by the tutors according to projects; In addition, due to the discipline feature, design graduates need to participate in many industry competitions or exhibitions, patent applications, etc.; In daily management, applications for personal leave, sick leave and suspension, exchange of studies, postponement of graduation, etc. need to be made online, and these needs to be approved and filed by the tutor and the school administrator; In order to improve the compactness of the management model, the platform requires the times of meeting a month graduate students and tutors to communicate academic progress. The student then records the meeting and submits it to the tutor for review.

\subsubsection{Tutor Terminals.}

The tutor's teaching tasks include teaching graduate students, producing and uploading study materials, exam scores, paper guidance, professional practice/social practice guidance and evaluation; The tutor's research tasks include applying for research projects, arranging research tasks for graduate students and guiding them.; The tutor conducts online approval for students' leave, suspension of study, exchange of study 
with foreign schools, as well extension of graduation; The tutor gives feedback to the students in the monthly report submitted by the system, and arranges the next step.

5.3.3 Management Department (Administrator) Terminals.

The administrator keep the assignments and results of the courses on file, and collect the results of teaching, scientific research and competitions between teachers and students; The administrator approvals and records the files, including student leave, suspension, exchange study and postponed graduation online; Managers review the monthly reports submitted by teachers and students, issue system documents and academic norms, publish industry competitions / exhibitions, internships / job hunting, cutting-edge results and other information, and manage the exchange platform; The management department sets deadline for each link, and the system reminds the teachers and students of the overdue and unfulfilled targets by email, and manages, supervises and evaluates the graduates and tutors according to the statistical data.

\section{Conclusion}

This study analyzes the problems existing in the current GMS through questionnaires, interviews, and puts forward the requirement and improvement plan of the proprietary platform for the design discipline. The functional framework of MCMSS for design subjects is constructed. This research will promote the improvement of the GMS development of practical work. Through the use of tripartite management and service system for graduate students, to strengthen the relationship between tutors and students, standardize graduate management, and provide students with targeted information disclosure and communication platform. This research provides a new way for the construction of management system of graduate education in universities.

Through the design of the information architecture, the system has been improved many times with advantage in following aspects: (1) The system emphasizes multiple participation of schools, university, tutors and graduate students to manages, supervises and evaluates the training process for graduate students. (2) The system regularly records the academic communication process between tutors and graduates, including monthly meeting content, assignment submission, paper guidance, internship suggestions, etc.(3) The content of management is more abundant and meticulous, which makes it convenient for tutors and colleges to track students, such as going out to practice etc. (4) Increase the platform for information disclosure and communication to the characteristics of design students and industry hotspots. (5) Strengthen the classification and archiving of design achievements; (6) Through the use of mega data, it can find students' research tendency, interests, innovations and other information.

\section{Acknowledgment}

This work was supported by a grant from the Guangdong Province Graduate Education Innovation Project (2016 JGXM-MS04)

\section{References}

[1]. B. Rubenstein-Montano, J. Liebowitz, J. Buchwalter, et al., A systems thinking framework for knowledge management, Decision Support Systems, 2008, 31(1):pp.5-16.

[2]. J. Zhang, Design and Implementation of the Postgraduate Education Management Information System, Hebei: North China Electric Power University, 2010. (In Chinese)

[3]. W. Wu, Evaluation and Design of Teachers in Graduate Education Management System (Diss.), Beijing University of Technology, 2015. (In Chinese) 